\title{
Teaching drunk: Work, the online economy, and uncertainty in action
}

\author{
Forthcoming in Philosophy \\ Runner-up, 2020 Philosophy Essay Prize
}

\author{
Max F. Kramer \\ University of Arizona
}

\begin{abstract}
Technological developments have led to the digitization of certain sectors of the economy, and this has many authors looking ahead to the prospects of a post-work society. While it is valuable to theorize about this possibility, it is also important to take note of the present state of work. For better or worse, it is what we are currently stuck with, and as the COVID-19 pandemic has ensured, much of that work is now taking place online. Though a 'return to normalcy' is on the horizon, part of that normalcy involves online work, which is itself a significant change in the lives of many workers. Here I develop an account of work on which work is teleologically structured. This gives the result that working is something we can fail at doing, even when we try, and we can also be unsure of whether we've succeeded or failed. The shift of certain work from in-person to online modes generates a persistent uncertainty for workers in those professions. Because our ability to work is something we typically value, this uncertainty has significant negative consequences for a worker's self-conception. Indeed, it is analogous to disorders of agency and generates a kind of alienation.
\end{abstract}

This is a penultimate draft of the paper, the published version of which can be found online at https://doi.org/10.1017/s0031819121000176. Please cite the published version.

§0. $\quad$ Prelude and background

Technological developments have led to the digitization of certain sectors of the economy, and this has many authors looking ahead to the prospects of a post-work society. While it is valuable to theorize about this possibility, it is also important to take note of the present state of work. For better or worse, it is what we are currently stuck with, and as the COVID-19 pandemic has ensured, a greater proportion of that work is now taking place online. Though there may be an eventual 'return to normalcy,' part of that normalcy involves online work, which is itself a significant change in the lives of many workers. Here I develop an account of work on which work is teleologically structured. This gives the result that working is something we can fail at doing, even when we try, and we can also be unsure of whether we've succeeded or failed. The shift of certain work from in-person to online modes generates a persistent uncertainty for workers in those professions. Because one's ability to work is something seen as valuable — given societal attitudes toward work, but equally given a Marxian conception of labour and creativity - this uncertainty 
has significant negative consequences for a worker's self-conception. Indeed, this uncertainty is analogous to disorders of agency and generates a kind of alienation.

\section{§1. Working is an achievement}

Work is a pervasive aspect of our social lives, both in its presence and absence. It significantly structures not only the use of one's time but one's very identity. When philosophers approach work as a topic of philosophical interest, it is typically from an ethical or economic perspective (e.g., Anderson, 2017; Cholbi, 2018; Gilabert, 2018). To my knowledge, there have been few if any attempts to examine work from an agentic perspective, that is, in terms of what sort of actions we are engaged in when we are at work and how we conceptualize what we are doing when we work. ${ }^{1}$ I suggest that understanding work as a species of complex activity permits novel insights into human agency and self-understanding. These insights will eventually reveal a concerning consequence of digitizing certain types of work.

A full metaphysics of work deserves its own treatment, but drawing a few distinctions will be necessary to illuminate aspects of work as they relate to human agency. The classic three-sector model in economics divides economies into primary, secondary, and tertiary sectors, where the primary sector extracts raw materials, the secondary sector comprises manufacturing, and the tertiary sector provides services within the society (Fisher, 1935). The first two sectors produce what we traditionally think of as commodities - items that you can buy, provided you have the money for them: food, lumber, steel, jumbo jets, houses, and so on. The tertiary sector instead deals with the exchange of services: retail, medicine, financial advice, and so on. I'll call labour ${ }^{2}$ that takes place in the primary and secondary sectors productive labour and tertiary labour service labour, and we can make similar distinctions between productive and service work, productive and service occupations, etc. This is not to say that service work and service labour are not productive, in a certain sense. It might be said that medicine, for example, produces healthy patients. But it is clear that the health of a patient and a commercial airliner are two very different

\footnotetext{
1 This is at least true of analytic philosophy. We find a discussion of labour, work, and action from a different philosophical tradition in (Arendt, 1998).

2 Throughout, I'll understand labour as (roughly) the exercise of labour-power, defined in Capital as 'the aggregate of those mental and physical capabilities existing in a human being, which he exercises whenever he produces a usevalue of any description' (Marx, 1867, Ch. 6). Labour is the stuff work is made of, but an exercise of labour will only count as work when it meets the teleological conditions enumerated below.
} 
kinds of products, requiring not only different skills and materials to produce them but also different kinds of labour.

This difference might at first appear to be a difference in the physicality of the commodity. Lumber, houses, and the like are extended in space, while health and advice are not. But this will not quite do, for retail jobs are prototypically service jobs, and yet this work clearly involves commodities that you can touch. Moreover, there are a great many digital commodities that are no more physical than advice or health are, and yet are intuitively the result of productive work.

The type of commodity involved in the work, therefore, does not suffice to capture the difference between productive and service work. A better strategy is to notice that work has a teleological structure. Commodities, whether physical or not, are not just a consequence of productive work - they are the point of work. Productive work aims at the creation of a certain commodity; the creation of the commodity is the telos of productive work. This is true regardless of what form the commodity takes, and why we can understand a potato farmer and a so-called 'content farmer' to be engaged in the same type of action. Both are exercising their agency in order to produce some commodity which can then be consumed, either as an input for a further productive process or as a consumer product.

In contrast, there is not a new commodity that comes into being as the result of service work, and this is not the aim of those professions. A salesperson does not create the stock that they sell. Rather, they take that stock and change something about it; namely, its ownership. Service work of this kind trades not in the creation of commodities but in their modification. Auto mechanics change your car from broken to fixed, waitstaff change your plate from empty to full, and so on. Yet, it is not quite right to say that modification is what is aimed at here. For, consider the paediatrician who sees patients for yearly check-ups. The patients are already healthy, and this is the paediatrician's apparent goal. Is there no work for the paediatrician to do? Of course there is. But here, instead of changing the child from sick to healthy, their task is to ensure or confirm that the child is healthy.

We can summarize this difference as follows: productive work is that which aims at the creation of new objects, whereas service work is that which aims at ensuring that certain objects have some appropriate status. This reinforces the sense in which productive work is productive: it brings something new into existence (acknowledging that it is all the same matter rearranged in different formats, of course), whereas service work only modifies, maintains, and confirms the 
status of already-existing entities. It is clear, then, that what differentiates service work from productive work is not the type of commodities it involves, but instead its aim with regard to those commodities. This is, at bottom, a difference in the telic structure of the respective forms of work.

I should also say something briefly about the relationship between work and occupations. I take it that the ultimate aims of some instance of work are the aims of the occupation or profession. So, while my proximate aim in removing a patient's cavity is to ensure that their tooth does not decay, my ultimate aim is ensuring their dental health more globally, because that is what the aim of dentistry is. This is what explains the fact that two work tasks can be identical yet have different aims depending on the professional context. For instance, the job of two different chefs may be to cook hot dogs, but the one who is a caterer contributes to the satisfaction of the event guests, while the one who works for the Nathan's Hot Dog Eating Contest contributes to the entertainment of viewers at Coney Island and watching on television. ${ }^{3}$

This does not mean that we cannot draw distinctions within the domain of service work on the basis of the type of object involved. In $\S 3$, I'll undertake a detailed investigation of teaching as a type of work. Intuitively, the work of a teacher is more akin to that of a paediatrician or an office manager than it is to an auto mechanic, and this has to do with the type of object involved in each profession. Teachers, paediatricians, and office managers are tasked with looking after the status of persons, while auto mechanics, plumbers, and brand managers are tasked with looking after the status of non-person objects. This does not mean that these latter occupations do not ultimately have an eye to the status of persons - after all, what is the point of repairing a toilet if not for the health and hygiene of persons? - but the objects with which they are proximately concerned are non-persons. We can therefore differentiate within the category of service work between personoriented service work and object-oriented service work.

Now, what are we to make of the teleology intrinsic to work? When some activity has a telos, it automatically has a normative standard to which it can be held. Consequentialism is a teleological theory because it evaluates an action as right just in case it achieves a valuable

\footnotetext{
${ }^{3}$ It's also important to note that many occupations will not deal exclusively in either productive or service work. A paediatrician, for example, may fashion a bandage in order to treat their patient, and this is an element of productive work that takes place in what is generally a service occupation. But here once again the teleology of work is instructive, for this productive task is ultimately put toward what we might call the ends of service. Thus, while we can acknowledge that service occupations may have productive elements and productive occupations may have service elements (e.g., a cobbler's job is to make shoes but they must sell those shoes to live), it will often be clear that the ultimate end of the work, the purpose for the occupation, will align more closely with one or the other type of work.
} 
outcome. Accruing value is the telos of right action on the consequentialist theory, and so an action only counts as right insofar as it works toward that end. In the same way, the telic nature of work means that some given exercise of labour only counts as a type of work insofar as it contributes to the end of the particular occupation. This entails that working is a kind of achievement; when one works, one has successfully contributed to the ends specified within the context of the profession.

This might at first appear to run contrary to natural intuitions about work. After all, aren't we working whenever we're 'at work', that is, clocked in to the place of business? Not so: to work, one must first labour, and an agent is clearly not labouring the entire time one is 'at work'. One is not labouring when one is on a break, for instance, even if this break takes place at the worksite. Some breaks are condoned by the terms of employment, others are not. Most of us are likely to have let our minds wander while we were supposed to be working, and based on the reaction of bosses, it is clear that this does not count as work. There is even a special term for this kind of notworking: loafing.

There are also times that we are working even though we are not in a location designated for work or outside the time typically designated for work. For example, a recent development is the permeation of email obligations beyond the working hours and beyond anything resembling a workplace. Many people report feeling as though they are still 'on the clock' when they are required to constantly be available for contact in this way. ${ }^{4}$

These observations suggest that a teleological view of work is not so far off from the everyday notion with which employers and employees operate. We acknowledge that we fail to work when we fail to contribute meaningfully to the task at hand (and therefore the goals of the profession), ${ }^{5}$ and we groan about the fact that we are working when we are compelled to contribute outside of working hours. Eventually, I will leverage this account of work in order to identify a disturbing side effect of digitizing certain professions. For now, though, we'll pursue an important consequence of this view: the fact that we have the potential to fail at working.

\footnotetext{
${ }^{4}$ This is a version of job creep, in which employees are pressured by their employers to contribute beyond the normal requirements of their job (Van Dyne \& Ellis, 2004). This concept is especially relevant to the blurred boundaries between work and leisure that come along from working from home and working online.

${ }^{5}$ To reiterate, although we fail to work when we make no contribution, this doesn't mean we haven't laboured. See note 2 above.
} 


\section{\$2. Failing to work}

There are a number of ways in which a person can fail to work, and in fact I have already discussed one. A person fails to work if they do not labour in the first place. This is what happens in at least some cases of loafing. One is intentionally refusing to engage in work, though one may be covering for it by attempting to appear to work. But more interesting are those cases when a worker attempts to work and fails. These can be roughly divided into internal failures - those that are attributable to something about the agent - and external failures - those that are out of the agent's control.

One internal source of failure is a lack of the general ability or abilities required to contribute to the end of the occupation. If I'm hired as a lumberjack, but I can't chop down a tree, then I won't be lumberjacking despite any labour I undertake. The confirmation that one has the requisite ability is a standard part of the hiring process, and part of why lying about one's credentials is seen as malfeasance over and above the lie itself. If one is simply unable to perform the tasks one is assigned as part of a job, then one is unable to contribute to the goals of the work for which one is contracted. ${ }^{6}$ The employee's actions in such a case can only amount to attempts at work, as actually working requires capacities that outstrip theirs.

Even if an agent has the requisite general ability to succeed at working, there are impediments that can prevent this success that are not up to the agent. Many work tasks require tools that are external to the agent. Continuing with the lumberjack example, one needs a saw in order to chop down a tree, granting that one has the know-how to do so. If a logging interest fails to provide its lumberjacks with adequate saws, then the lumberjacks will not be able to complete their work, even if they have the general ability to do so. The internal/external distinction here roughly tracks the distinction between general and specific abilities (e.g., Graham, 2011), and also suggests a heuristic for attributing responsibility for failures to work, since external failures are typically the result of internal failures on the part of bosses and co-workers (the thought being that we are solely responsible for internal failures, but at least partially excused when failure is attributable to others). However, the fact that a worker is blameless for an external failure of this kind does not change the fact that they still failed to contribute to the ends of their work, and

\footnotetext{
${ }^{6}$ Here is may be useful to clarify that one can work poorly while still working (as opposed to merely attempting to work). Working involves making a contribution, whether that contribution be big or small, proportionate to the amount of labour invested or not. Admittedly, there may be boundary cases where a contribution is so small or so disproportionate that it verges on a failure to work, but this shouldn't count against the distinction being made in general. Thanks to an anonymous reviewer for drawing my attention to this.
} 
therefore can only be said to have laboured, only attempted to work, rather than succeeding in this attempt and converting labour into work. ${ }^{7}$

Inability, whether general or specific, consigns a worker to failure from the start. However, there are other failures that have more to do with the worker's conception of what they're doing than their physical abilities. While successfully working doesn't require one to have a proper conception of the ends at which one is aiming, ${ }^{8}$ one is likely to be more reliable the better one understands where one is directing one's effort. Recall the type of ends at which work aims: productive work aims at the creation of a particular commodity, while service work aims at securing a particular status of a particular object.

If an agent engaged in productive work is mistaken about the kind of commodity they are tasked with producing, their labour is likely to be misdirected. This requires a particularly high degree of ignorance in some cases - imagine a lumberjack who takes their goal to be some quota of Aston Martins sold above MSRP - but slightly less in others. For example, assume that the end of moviemaking is to realize a director's artistic vision, and thus a writer's job is to produce a script that crystallizes that vision on paper. ${ }^{9}$ If the writer thinks the movie is supposed to be about the love between two characters, but it's really supposed to be about the social conditions under which their relationship plays out, then the writer may only be attempting to write the appropriate movie script, rather than succeeding in doing so. This is true even if the failure is understandable due to the difficulty of properly identifying the goal of the work. ${ }^{10}$

\footnotetext{
${ }^{7}$ We might be tempted to think that a similar thing happens when an agent works with others in pursuit of a general goal and those co-workers fail to carry their end of the bargain. However, this is not always the case. A worker can still contribute to the ends of work even if those ends are not ultimately met, because work is a collaborative process. Imagine an assembly worker who adequately does their task and passes it along to the next link in the chain. If there's a failure downstream, this does not invalidate the contribution the worker has already made. This stands in contrast to the case described above, where the company's actions prevent the worker from making any contribution at all. Therefore, not all failures of joint agency constitute failures to work.

${ }^{8}$ To draw an analogy with ethics, the view I'm offering here is similar in structure to views that do not require an agent to conceive of an action as right, or even act in virtue of the right-making features of the action, in order to engage in right action. Nomy Arpaly's cases of inadvertent virtue illustrate a similar phenomenon (Arpaly, 2002).

${ }^{9}$ An anonymous reviewer rightly points out that this could operate in reverse. A writer could write a script and a director could choose to turn it into a film, but have different ideas about the meaning of the story than the writer did. In this case the director would be failing to realize the writer's vision, but successful in realizing their own. Whether this constitutes failure depends on whether we endorse an auteur theory of cinema, as I do above, or something more focused on the story itself. For example, it's easy to see this variation on the case as a failure if the director is adapting a beloved piece of written fiction and failing to do it justice.

${ }^{10}$ It's important to acknowledge that it is no easy feat to determine the ends of particular work or a particular occupation. This is a task best left to those who are stakeholders in these occupations. For example, we see a spirited debate about the point of producing art among artists, art theorists, and art collectors.
} 
Ignorance about the ends of service work follows along similar lines, except there are two components of the end to get wrong: the object of the work and the status of the object to be achieved. Both seem to be pretty egregious misconceptions of what one is supposed to be doing. One could imagine a novice car salesman being taken under a veteran's wing and being told, 'Your mistake is that you think this job is about selling a car - it's not. This job is about making people happy.' If the novice takes this literally, they may fail because they misunderstand the point of their work; this dictum ought to be taken as advice about the best means of achieving the end of making sure the car is sold. If the novice, following the word of the advice but not its spirit, fails to sell any cars, they will have a hard lesson in what the object of their profession really is. Likewise, there are few reasonable misunderstandings of the status that is supposed to be secured by some particular work. One would question the seriousness of an auto mechanic who replied to dissatisfaction at their work with, 'Oh, I didn't realize that I was supposed to make sure the car was running well,' and it seems like they are at best merely attempting to work at their profession.

A more understandable kind of ignorance that leads to failure is an ignorance of the conditions under which a contribution is made to some end, even if that end is properly identified. Put differently, these failures involve an understanding of goals de dicto but not de re, and this leads agents to choose insufficient means to the ends of their profession. In productive work, this would involve an agent who is mistaken about whether their labour actually contributed to the creation of the commodity. One can imagine a worker who is tasked with making gaskets for washing machines. They know that well-made gaskets are a necessary part of a washing machine, but they are bad at making gaskets because they don't understand what gaskets actually contribute to the machine's functioning. Every day, their long-suffering colleagues have to reshape the gaskets they produce in order for them to fit appropriately with the rest of the machinery. This worker is under the impression that they have put in an honest day's work, but they have failed to work at all, in the relevant sense. ${ }^{11}$

In the service work case, this variety of internal failure is connected to a mistake about what it takes for the object to achieve the requisite status. Compare to the misguided auto mechanic from before, who didn't realize that the status of the car to be achieved was its running well. The mechanic who arrives at the present kind of failure understands that their work consists in making

\footnotetext{
${ }^{11}$ As this example suggests, this genre of internal failure is related to internal failures arising from inability. Here, though, the inability is not apparent to the worker.
} 
sure the car runs well, but is mistaken about what counts as running well. Perhaps the mechanic believes that cars run well for general use when they can drive at their fastest, whereas cars in fact run well when they can drive the longest on a single tank. ${ }^{12}$ Where previous internal failures have resulted from factual mistakes regarding the ends of work, this type of failure arises from conceptual mistakes about which states of affairs satisfy a certain condition. This is even more visible in a case from person-oriented service work. The status that the medical profession tends to be concerned with is that of health, but the nature of health is significantly in dispute, both among theorists and laypeople. When a licenced medical doctor recommends parents to vaccinate their child and an alternative medical practitioner warns the same parents away from vaccination, both conceive of their actions as pursuing the correct end: ensuring that the child is healthy. Unless we are relativists about health, they can't both be right, and as such, they both can't be practicing medicine - at least one of them is labouring with the intent to do so, and not succeeding.

The normative aspect of work also shows up as a key component of certain external failures in person-oriented service work. For these to be external failures, it must be the case that the agent has done everything they can do, and yet failed to succeed in directing their labour appropriately. To continue in the medical context, a doctor can fail to make a contribution to a patient's health, even if they have the appropriate conception of health that they aim toward in their action, if the patient fails to disclose crucial information to them. ${ }^{13}$ The lack of participation on the part of the patient blocks the doctor from doing their work.

There is another kind of participation in person-oriented service work that is more central to the normativity of certain work. Person-oriented service work focuses on the statuses of persons. Because persons are subjects in their own right, it is plausible that they have some say in whether a status that applies to them has been achieved or not. Health is a prime example of a status of persons that may have an irreducibly subjective element. That is, it may be partly up to an individual whether they are healthy or not, perhaps because health has to do with whether they meet standards of function that the subject gets to set for themselves. This would mean that, regardless of what a doctor does, it is in some respect up to the patient whether they are healthy,

\footnotetext{
12 An equivalent mistake would be made if the mechanic believed that cars run well for use in racing when they sacrifice speed for efficiency. Thanks to an anonymous reviewer for pointing this out.

${ }^{13}$ If we conceptualize patient disclosures as a kind of tool that the doctor needs to work, then this has the same structure as the lack-of-specific-ability cases above.
} 
and therefore up to the patient whether the doctor has succeeded in contributing to the end of their work.

When work deals with persons rather than commodities, a worker must depend on the client or consumer in order to achieve what they are contracted to do by their profession. This opens the door for the worker to fail even when they put forth their best effort, and illustrates the way in which a certain type of work - specifically, person-oriented service work - is a mutual activity, in which contributions from both parties are essential to whether the exercise of labour generates value. In the remainder of the essay, I'll discuss how this creates an essential uncertainty from the worker's point of view and consider one case in which the digitization of work transforms this uncertainty into a novel sort of alienation faced by the modern and future worker.

\section{§3. Uncertainty in action: The case of teaching}

Let's clarify where we are. I developed an account on which work is teleologically structured and divided work into productive and service forms, differentiated by the type of ends it has. Within service work, I subdivided the category on the basis of whether the occupation primarily dealt with persons or non-person objects. I then discussed the way in which this teleological structure entails that to work at a particular profession is a kind of achievement, and that there are many ways of failing to work. Most of these failures involve the agent labouring but failing to make contributions to the appropriate ends, due either to internal or external factors.

The point of this discussion, in particular the section on failure to work, is to draw attention to the exercise of agency that work consists in. Our sense of agency is integral to our selfconception, and working status typically is as well. We can create a link between these two objects of importance because we have conceptualized what an agent is doing when they work as an exercise of agency. Failure to effectively exercise one's agency, especially toward the attainment of goals that are at least instrumentally important to the agent, has significant psychic consequences. If a basketball player simply cannot make free throws, they will start to doubt their status as a basketball player. If this is a social role that is important to their self-conception, they will start to have doubts about their own sense of self: 'If I'm not a basketball player, then what am I?' This is not to say that all agents take their occupational status to have significant bearing 
on their identity. ${ }^{14}$ But it is true that, in economically developed societies, there are serious social stigmas against those that fail to contribute to the economy through their labour. This is especially true in more conservative societies such as the United States, where attitudes toward welfare programs and the people who depend on them typically range from neutral to outright hostile, depending on who you ask. ${ }^{15}$

This relationship between failures of agency in work and negative self-conception is interesting, but it does not yet say anything distinctive about the impact of new modes of work, particularly online work. In fact, online work and online distribution of social welfare benefits may seem to fight against this current, since these transitions would shield a worker's failures from the public eye. If we are going to identify a way in which specifically online labour has an impact on a person's agency and self-conception, it will have to be something more internal, more personal.

The types of failures I enumerated at the end of the previous section contain the germs of such a phenomenon, though it will take some further effort to develop. The first important thing to notice is that certain types of failures to work - especially internal failures - may go unnoticed by the worker. This is true of failures that result from ignorance, either of the proper ends of the worker's occupation or the necessary means to those ends. Because they have misconceived of the goals on the basis of which they are acting, they will not realize that they have misdirected their labour until they correctly identify the ends or what constitutes a contribution to those ends. This realization will hopefully come after one instance of failure, since what we are dealing with is a factual error, easily corrected either by the worker themselves or by their supervisor. Still, when one is new at a job, the possibility of factual error may hang over one's head like a dark cloud, breeding an uncertainty about whether one is exercising one's labour appropriately or not.

This dark cloud is one that is easily dissipated through experience. Yet, a more persistent uncertainty would threaten a worker's sense of agency more significantly, for if a worker were under conditions where they were required to act, but never or rarely assured about whether they

\footnotetext{
${ }^{14}$ Individuals may (and often do) take up work for other reasons than valuing the end of their work. For example, a person may choose to be a lumberjack not because they care about providing people and businesses with lumber but because it affords a nice physique. But this doesn't mean that the status of their labour, e.g., whether they succeed at lumberjacking, depends on their reasons for taking up the work - it is dependent on the nature of the work itself.

${ }^{15}$ I don't mean to suggest that every American explicitly holds discriminatory beliefs toward welfare recipients, though there is good evidence that American research populations have implicit biases against the poor, especially when the poor are racialized (Brown-Iannuzzi, Cooley, McKee, \& Hyden, 2019). I also don't in any way intend to endorse this hostility, explicit or implicit, toward social welfare programs or recipients. In fact, the analysis I've provided thus far strongly suggests that we should work to reduce this stigma, especially due to the possibility of external failures to work.
} 
were succeeding or not, this uncertainty stands to be internalized in their self-conception just as persistent failure does. I submit that persistent uncertainty is something that may face agents employed in certain newly-online professions, such as teaching.

Factual errors are a poor candidate for persistent uncertainty because they are easily cleared up, but they are not the only type of errors that result in failure to work. Another sort of failure arises from conceptual error, especially when one is mistaken about the nature of some normative concept, such as health or well-being. Unlike factual errors, which can be corrected (often relatively easy) by empirical means, normative disputes are notoriously thorny and difficult to resolve. Without referencing thousand-year-old debates in philosophy over the nature of wellbeing, the good, the right, and so on, one may look to contemporary public debates over the status of vaccination in relation to health or the status of the Black Lives Matter movement in relation to justice to see the persistent disagreement that surrounds these concepts.

The subject of deep normative disagreement has recently been thoroughly examined in epistemology. On one side stand the conciliationists (e.g., Christensen, 2007; Elga, 2007), who claim that disagreement counts as a reason to believe not- $p$, given that one believes $p$; on the other stand defenders of steadfastness (e.g., Foley, 2001; Wedgwood, 2010), who claim that an epistemic agent in a peer disagreement can permissibly stick to their guns, belief-wise. ${ }^{16}$ Regardless of one's view about what is rational to do in the context of normative disagreement, it is at least understandable that an agent who became aware of differing normative views would become less certain of the truth of their own normative view. Many of the statuses that person-oriented service work aims at are not only normative, they are the subject of active disputes as to how one should properly understand them. The presence of such disagreement may therefore lead a personoriented service worker to become uncertain that they are actually making a contribution to the ends of their profession, and this uncertainty will not be easy to resolve because they will lack easily accessible evidence that would lead them back to certainty.

As with factual-error-based-uncertainty, the uncertainty that arises from the possibility of normative-conceptual error is not unique to professions that have changed with the rise of online technologies, as there is no reason to think that all such professions uniquely involve normative

\footnotetext{
${ }^{16}$ These views are actually supposed to apply to all forms of peer disagreement. I have the impression that it is usually clearer who is in the right and who is in the wrong for factual disagreements that arise in the context of work, which would make it appear that conciliation seems the only rational response in those cases. However, I don't have the space or inclination to defend this claim here, nor is it necessary to the general thrust of the argument.
} 
statuses. However, it does indicate that we should be attending to the kind of profession with the potential for normative-conceptual error - which is to say, person-oriented service professions within the category of those professions affected by digitization if we are interested in the possibility and prevalence of persistent uncertainty.

As we'll recall, there was a further potential for failure in person-oriented service professions on account of their aiming at normative statuses of persons, since the achievement of some such statuses requires participation and engagement on the part of the person who is the object of the work. Return to the medical example: if what it is for someone to be healthy in part depends on their own attitudes, then whether a medical professional brings them to a state of health or not depends on whether they have appropriate attitudes in response to the labour of the medical professional. $^{17}$

In some service professions, it will be clear whether the person who is the object of work is engaging with the worker's labour in a way that renders it a contribution to their status. For example, a medical patient who expresses gratitude and appreciation for a doctor's efforts has clearly been made healthy, provided that other objective conditions of health have been met. ${ }^{18} \mathrm{We}$ can also see this kind of engagement in artistic work: a stand-up comedian, for instance, will only know that their labour has been directed successfully if the audience is laughing. It is also crucial that part of the worker's labour in these occupations involves attempting to secure this engagement. This is plausibly why doctors, if they are to succeed in curing patients, also make efforts to explain why and how they are performing certain medical procedures. The more that a patient understands the purpose of the labour from the doctor's point of view, the more they are likely to receive that treatment as a legitimate contribution to their health and well-being. Securing engagement also involves careful monitoring of the object of the work. This is why a stand-up comedian must always be paying attention to their audience to see which material 'works' and which does not. This attention to the reception of the worker's activity fosters a kind of flexibility in labour, where the worker chooses to exert their agency in variegated ways in order to try to secure the participation that they recognize is constitutive of the success of their work.

\footnotetext{
17 One view in this neighbourhood is Eva Feder Kittay's, who emphasizes the importance of subjectivity in her disability-focused articulation of care ethics. She holds that if the subject does not receive a certain action as caring, then it fails to count as care in the relevant (normative) sense (Kittay, 2019).

${ }^{18}$ Remember, it need not be the case that health (and other normative statuses) are wholly subjective, just that there is some irreducibly subjective component to them.
} 
All this is certainly true of teaching as well. Teaching provides an interesting case study of a profession that has been rather suddenly taken online, especially as a response to a pandemic. Some forms of online teaching straightforwardly attempt to reconstruct the in-class experience of teaching using digital technologies. Crucially, these forms of teaching are synchronous, meaning that instruction is delivered and received in real time. In contrast, other forms are asynchronous, meaning that there is a time lag between the instructor recording and uploading a lecture and a student viewing or listening to it. Synchronous teaching is basically a temporary stand-in for inperson instruction, but asynchronous courses represent a genuine shift in the structure of teaching in accordance with the shift in the medium by which teaching is done. These courses attempt to use digital tools not to reconstruct the classroom, but to revolutionize it, especially for the purposes of flexibility in teaching and learning. This is work that has been transformed by online technologies, and therefore presents a good case to test the impact of this technological shift on the experience of the worker.

So, what is it like to teach asynchronously online? We can take up this question by drawing on the resources I've developed thus far, especially in light of the psychic threat of uncertainty in whether one is or is not succeeding at working. Though I don't expect any particular end of teaching I put forward will be uncontroversial, I think we can safely assume two things. The first is that the object of teaching is the student, or the students collectively. This is the thing that receives attention in teaching, and it's what classifies teaching as a kind of person-oriented service work. The second is that, as in medicine and other forms of person-oriented service work, whatever status is supposed to be achieved requires the engagement of the object of work, namely, the student. This is just to say that, for a person to be teaching, it is not only necessary for there to be a student, but that student must in some way be engaged in the pedagogical activity. This is why it is impossible for a rock or a lake or a building to be a proper student: these things aren't able to receive teaching in the appropriate way. It's also why a teacher might say after a particularly wooden and awkward class that they 'just weren't able to get any teaching done today.' For teaching to succeed in any amount, it must be taken up by students as effective.

If these two conditions on teaching as work are correct, then we have all that we need to show that asynchronous online teaching breeds a particularly nasty kind of uncertainty in action. In in-person and synchronous online teaching, the labour put forward by the teacher and the participation of the students happens in tandem. The teacher lectures, the students engage, and so 
it is fairly clear to the teacher whether they are succeeding at teaching or not. In asynchronous online courses, the lack of synchrony forbids such knowledge. This is because the labour of the teacher and the participation of the students are temporally distant from one another. As such, at the time that the teacher exercises their agency in an attempt to work, they are in principle forbidden from knowing whether they are succeeding or not. ${ }^{19}$ At best, they can attempt to discern at a later date whether their labour was effectively directed through student examinations, homework assignments, and so on. Yet, even these measures do not confirm that they were teaching. It is possible that their labour was totally inefficacious in securing the requisite status in their students, and the students who took up the effort to achieve that status themselves did so by becoming autodidacts.

This uncertainty is perhaps most forceful when we imagine the teacher asking a rather innocuous question of themselves: when am I teaching? I see three possible options, none of which secure any real certainty.

The first is that they are teaching when they record and upload their lectures. This option excises any consideration of student engagement and cannot possibly be seen as fulfilling the obligations of teaching from their perspective. For all they know at this point, not a single student will watch or listen to their lecture, leaving them in the same circumstances as a teacher who lectures in front of a totally empty classroom.

The second option is that they are teaching when their students put forth the necessary participation. However, this gives some fairly unintuitive results. From my own experience, students often send emails in the middle of the night, and I can only presume that this is when some would watch or listen to lectures for their online classes. Does this mean that I am teaching while I am sound asleep? According to this response, we are compelled to say yes. In fact, if this response is correct, then there is even less certainty than in the first case, since I could be teaching while I am doing anything else: going for a run, getting a manicure, even indulging in a long night of drinking. It typically seems like poor form to teach drunk, but this response would have us say that it is a distinct possibility, and unproblematic!

\footnotetext{
${ }^{19}$ This may be appealing if one is a knowingly poor teacher - the uncertainty of whether one has done a good job or not can be preferable to knowing for certain that one has failed (again, when one values being competent at one's work). Thanks to an anonymous reviewer for the case.
} 
The last option is to say that the activity of teaching is an event that spans both the duration of the teacher's labour output and the students' participation. This not only inherits the same uncertainty as the second option (though tempered by the fact that it includes a component over which the teacher exerts control), it is a bit of a metaphysical puzzle. This is because the temporal boundaries of the event could only be determined once the first student participates, since this is what makes it the case that the teacher's labour output is a part of the event of teaching, rather than a standalone event of attempting to teach. Perhaps this just means that teleologically-defined complex actions present general metaphysical quandaries, and I don't intend to dispute this thesis. But what is more important for our purposes is how the teacher is supposed to conceptualize their own activity in a way that impacts their sense of self, and the fact that they are faced with uncertainty about whether they are succeeding at teaching on any of these accounts of online teaching bodes poorly for these workers' psyches.

It should also be noted that, unlike in synchronous modes of teaching, asynchronous teachers are closed off from the methods by which they can secure engagement from their students if it is not forthcoming. I mentioned previously that part of person-oriented service work is exercising one's agency in a flexible way, achieved by paying sufficient attention to the participation by the person or persons in question. In a classroom, this might mean reminding students of rules about participation, calling on students who seem checked out, or otherwise provoking engagement when it is lacking. The temporal lag in asynchronous teaching forbids this kind of flexibility. It is true that even in the classroom, teachers lack full control over whether their students participate, but at least they have the opportunity to try to influence participation. This opportunity is not present when the teacher's labour output is temporally sequestered from even the possibility of student participation.

This poses an even greater challenge to the teacher's self-conception when we consider how flexibility is evaluated in the context of the activity of teaching. Teachers who are very good at reliably securing substantial and enthusiastic participation from their students, just like comedians who are very good at rearranging and shifting their acts based on the audience, are seen as excelling at their profession. To draw an analogy, a stand-up with only one version of their act can never be a great performer, even if that act is very funny. The fact that online asynchronous teaching forbids the possibility of exercising these relational virtues means that online teachers are prevented from being excellent at their profession. If success at one's job is something that matters 
to an agent, then this is a serious harm - and it's something that only arises because the modern teacher's work takes the particular digital form that it does.

\section{$\$ 4$. Alienation from labour 2.0}

In this essay, I have tried to illustrate not only how failing to work can lead to poor consequences for an agent, but how mere uncertainty about whether one's labour is exercised effectively does as well. I have also shown how exercising one's labour online, rather than in person, can exacerbate and in fact ensure this kind of uncertainty. However, I only did so using one example, that of online teaching, and it may be charged that this is an isolated incident rather than a general trend to ward off as modern economies are further digitized. In closing, I'll attempt to offer some reasons to think that this may be a more global phenomenon.

First, we have to recognize that the specific and persistent uncertainty that is endemic to online teaching occurs because teaching is a type of person-oriented service work, and this type of work typically involves a contribution from the person who is the object of the work. Compare this to an example of object-oriented service work: fixing a car. If we imagine what this work would look like in an online space, it may be that a mechanic receives information about the functioning of the car and then uploads a set of commands for diagnostics and fixes to be carried out remotely on the car by some kind of robot. The car doesn't care whether those commands are enacted synchronously or asynchronously, because the car can't care about anything; the mechanic doesn't need input from the car in the same way a teacher needs input from their students.

There are some reasons why the mechanic may prefer to work synchronously, but these would all have to do with error detection in the choice or enactment of the commands. Synchronous online vehicle servicing allows the mechanic to recognize when they have made a mistake or if the robot enacting the commands is malfunctioning, but this is no different than the general uncertainty in productive work that one has made a mistake or that one's tools are malfunctioning. It might salvage a particular attempt at work to be aware of these failures as they happen, but the time difference between a synchronous and asynchronous mode of online object-oriented work does not pose any significant threat to the worker's overall conception of themselves. One can still be confident that one is an exceptionally successful auto mechanic and have a sense that one is in control of one's efforts at working even if the results of one's labour are temporally segregated from its exercise. 
This latter point represents the real difference between object-oriented and person-oriented service work that is made asynchronous through digitization. A worker who does not have to deal directly with persons maintains the same sense of control over their work as if it were synchronous, but a worker who deals with persons does not. When working with persons, an agent already cedes a degree of control because part of what renders their labour work in the relevant sense depends on a contribution from the other person. But this lack of control is exacerbated when one can only blindly offer their labour out into the world, not knowing until later, if at all, whether it was properly received. This will be true of all person-oriented service work, not just teaching.

I have mostly discussed this lack of control in terms of the importance of successful work to the worker's self-conception, but there is also a more general concern about the success of the worker's agency and the importance of agency to any person's self-conception. We can never be secure in knowing that our attempts at acting will be carried out successfully, but we tend to accept a degree of uncertainty as a by-product of the fallibility of our bodies and the world's indifference to our intentions. If I aim to sink a free throw in a basketball game and a gust of wind makes the shot clang off the backboard, this is something I can happily accept - I don't internalize this as a mark against my specific capacity to make free throws or my general capacity to act intentionally. But the asynchronous online teacher, and any other asynchronous person-oriented service worker, must make do with a lot less control over the status of their actions than others. Not only are they unsure whether their attempts at action are successful, they are prevented from knowing at what point in time their successful actions even take place. Much is made in the action theory literature about the kind of control that comes from an intention resulting in an action (Mele \& Moser, 1994, pp. 62ff), but little is said about the possibility that the time at which their intention comes to make the proper impact on the world is radically undetermined from the agent's point of view.

We can see this more forcefully by considering how modes of agency that are deemed disordered all involve a lack of the appropriate connection between intention and behaviour. What is disordered about agency in the throes of addiction, for example, is that agents do not have control over what they do, because their behaviour is sourced from outside the will (or your favourite naturalistic equivalent, e.g., the 'reward system' in Arpaly \& Schroeder, 2013). But notice also that a person could in some respect endorse the desires that arise from their addiction, and yet still be disordered insofar as they are unable to exercise control over when those desires are acted upon. Consider the case in which a cocaine user decides at the beginning of the day to use cocaine during 
their afternoon smoke break, but is compelled to indulge during their lunch break instead. What's disordered is not that this agent is using cocaine against their will, because they're fine with using cocaine. It is rather that they do not have control over when they use it. We might also see a similar situation in a person with Tourette's syndrome. Perhaps they fully endorse as their own the desire to act out a certain gesture, but as long as they lack control over when these gestures occur, we are still inclined to think that their agency is disordered in some way.

The online service worker finds themselves in a similar situation to these disordered agents. They endorse their behaviour as their own, but lack a sense of control over it, because they do not know when it occurs. And don't forget that this is what happens in the best-case scenario, that in which their labour secures the required participation from their client - information they are also deprived of! These workers are, in a sense, alienated from their own actions, and specifically their labour. But this is not the kind of alienation from labour that Marx talked about, in which a worker is separated from the product of their labour or in which a worker is coerced to sell their labour because they would otherwise starve. In this case, the worker's alienation must be understood in an action-theoretic sense. In fact, it is not quite right to say they are alienated from their labour they are alienated from the status of their labour, which in turn foments an alienation from their sense of agency and sense of self. And, unlike the orthodox Marxian line, this alienation is only due to the economic conditions in which they labour in a quite roundabout way; namely, that these economic conditions are what prompted their occupation to be shifted online.

If this is the fate of person-oriented service workers whose jobs are taken online, then this is a significant consideration in the ongoing conversation about the new modernity of the digital economy. Just as it is important to consider what impact automation will have on people when their jobs are erased, it is important to consider what is currently happening and due to happen in the near future as real people are placed into those roles that will soon be automated. Halfway between the future and the past, we see, is no comfortable place to find oneself. ${ }^{20}$

\section{$\underline{\text { References }}$}

Anderson, Elizabeth. (2017). Private Government: How Employers Rule Our Lives (and Why We Don't Talk about It). Princeton University Press. https://doi.org/10.2307/j.ctvc775n0

\footnotetext{
${ }^{20}$ I would like to thank Michael McKenna, Maria Seim, and Robert Wallace for their conversation and feedback in the development of this paper. I am also grateful to a coterie of anonymous reviewers at Philosophy for their insightful comments and careful attention.
} 
Arendt, Hannah. (1998). The Human Condition (2nd ed.; M. Canovan, Ed.). University of Chicago Press. https://doi.org/10.7208/chicago/9780226924571.001.0001

Arpaly, Nomy. (2002). Unprincipled Virtue. Oxford University Press. https://doi.org/10.1093/0195152042.001.0001

Arpaly, Nomy, and Timothy Schroeder. (2013). In Praise of Desire. Oxford University Press. https://doi.org/10.1093/acprof:oso/9780199348169.001.0001

Brown-Iannuzzi, Jazmin L., Erin Cooley, Stephanie E. McKee, and Charly Hyden. (2019). Wealthy Whites and poor Blacks: Implicit associations between racial groups and wealth predict explicit opposition toward helping the poor. Journal of Experimental Social Psychology, 82, 26-34. https://doi.org/10.1016/j.jesp.2018.11.006

Cholbi, Michael. (2018). The desire for work as an adaptive preference. Autonomy, 4, 1-17.

Christensen, David (2007). Epistemology of Disagreement: The Good News. Philosophical Review, 116(2), 187-217. https://doi.org/10.1215/00318108-2006-035

Elga, Adam. (2007). Reflection and Disagreement. Nô̂s, 41(3), 478-502. https://doi.org/10.1111/j.1468-0068.2007.00656.x

Fisher, Allan G. B. (1935). The clash of progress and security. Macmillan.

Foley, Richard. (2001). Intellectual Trust in Oneself and Others. Cambridge University Press. https://doi.org/10.1017/CBO9780511498923

Gilabert, Pablo. (2018). Dignity at Work. In Pablo Gilabert (Ed.), Philosophical Foundations of Labour Law (68-86). Oxford University Press. https://doi.org/10.1093/oso/9780198825272.003.0004

Graham, Peter A. (2011). 'Ought' and Ability. Philosophical Review, 120(3), 337-382. https://doi.org/10.1215/00318108-1263674

Kittay, Eva Feder. (2019). Learning from My Daughter: The Value and Care of Disabled Minds. Oxford University Press. https://doi.org/10.1093/oso/9780190844608.001.0001

Marx, Karl. (1867). Capital (Vol. 1; B. Fowkes, Trans.). Penguin Books.

Mele, Alfred R., and Paul K. Moser. (1994). Intentional Action. Noûs, 28(1), 39. https://doi.org/10.2307/2215919

Van Dyne, Linn, and Jennifer Ellis. (2004). Job creep: A reactance theory perspective on organizational citizenship behavior as over-fulfillment of obligations. In J. CoyleShapiro, L. Shore, M. Taylor, \& L. Tetrick (Eds.), The Employment Relationship: Examining psychological and contextual perspectives (181-205). Oxford University Press.

Wedgwood, Ralph. (2010). The Moral Evil Demons. In Richard Feldman \& Ted A. Warfield (Eds.), Disagreement (216-246).

https://doi.org/10.1093/acprof:oso/9780199226078.003.0010 